\title{
Modern Directions for Potentiometric Sensors
}

\author{
Eric Bakker*,a,b and Karin Chumbimuni-Torres ${ }^{b}$ \\ ${ }^{a}$ Nanochemistry Research Institute, Department of Applied Chemistry, Curtin University of Technology, \\ WA 6845 Perth, Australia \\ ${ }^{b}$ Department of Chemistry, Purdue University, IN 47907 West Lafayette, USA
}

\begin{abstract}
Este artigo apresenta uma revisão dos mais recentes progressos dos eletrodos íons-seletivos de membrana polimérica. É discutida uma essência curta da teoria básica, enfatizando como a força eletromotriz pode ser usada para calcular as constantes de ligação do ionóforo, e como a seletividade e o limite de detecção estão relacionados aos processos de membrana mais importantes. Os recentes progressos na diminuição dos limites de detecção dos ISEs são descritos, incluindo recentes tentativas no desenvolvimento de ISEs de contato sólido, e inovações na detecção de quantidades ultra-pequenas de íons em baixas concentrações. Esses progressos têm alçado o caminho para usar sensores potenciométricos em bioanálise com afinidade ultra-sensível junto com nanopartículas usadas como marcadores. Os resultados recentes estabelecem que a potenciometria compara-se favoravelmente com a análise de redissolução eletroquímica. Outros novos progressos com os eletrodos de íon-seletivo são também descritos, incluindo o conceito de potenciometria de calibração interna, coulometria de corrente controlada, cronopotenciometria pulsada, e titulação rápida localizada com membranas íon-seletivas para desenhar sensores de detecção direta da acidez total sem perturbação da amostra. Estes progressos têm aberto um amplo campo para novos desenvolvimentos e aplicações nesta área.
\end{abstract}

This paper gives an overview of the newest developments of polymeric membrane ion-selective electrodes. A short essence of the underlying theory is given, emphasizing how the electromotive force may be used to assess binding constants of the ionophore, and how the selectivity and detection limit are related to the basic membrane processes. The recent developments in lowering the detection limits of ISEs are described, including recent approaches of developing all solid state ISEs, and breakthroughs in detecting ultra-small quantities of ions at low concentrations. These developments have paved the way to use potentiometric sensors as in ultra-sensitive affinity bioanalysis in conjunction with nanoparticle labels. Recent results establish that potentiometry compares favorably to electrochemical stripping analysis. Other new developments with ion-selective electrodes are also described, including the concept of backside calibration potentiometry, controlled current coulometry, pulsed chronopotentiometry, and localized flash titration with ion-selective membranes to design sensors for the direct detection of total acidity without net sample perturbation. These developments have further opened the field for exciting new possibilities and applications.

Keywords: ion-selective electrodes, potentiometry, trace level analysis, affinity bioassays, flash titrations

\section{Introduction}

Ion-selective electrodes (ISEs) are an important class of chemical sensors that has found widespread use today in a number of routine applications. A key driving force for their development was their implication in automated clinical analyzers for the high throughput determination

*e-mail: bakker.eric@gmail.com of electrolytes in physiological samples. ${ }^{1}$ Indeed, ISEs of very much the same chemical composition are today used in such clinical analyzers, be it large comprehensive instruments housed in centralized laboratories of hospitals, more compact benchtop systems that can be placed in the practitioner's hands, or even the handheld bedside testing systems that have become available in recent years. This success story is largely attributed to the creativity and determination of scientists in the 1970s, at a time when 
ion-selective electrode research captured the fascination of a generation of scientists and was displayed as lead articles in top journals such as Science. ${ }^{2}$

As sometimes is the case, the commercialization success of the technology was followed by a relative lull in research activity, and it is only in the last 10 or so years that the field has been re-invigorated with new faces and fresh ideas. We summarize here some of these newest advances.

\section{General Principles}

A measurement in potentiometry is, as everybody knows, conducted in a two electrode galvanic cell under zero current conditions. With ion-selective electrodes, one is the reference electrode and the other the so-called indicator electrode. The reference electrode has not really changed in its fundamental design in the past 100 or so years and relies on an aqueous bridge electrolyte (classically a $\mathrm{KCl}$ solution of high concentration) in contact with the sample solution via a liquid junction. Depending on the application, the design of the reference electrode can be simplified. In clinical applications, for instance, the reference electrolyte may be electrolytically matched to the sample and connected to the sample stream via a simple flow bridge without the need for a classical junction material. In ideal cases, the electromotive force is proportional to the logarithm of the ion activity in the sample according to the well known Nernst equation, see below.

The key material in the cell, of course, is the ion-selective membrane. Traditionally, it separates the sample solution from an aqueous internal solution in which an internal reference electrode is placed. A range of different materials have been explored for their ion sensing characteristics, including doped silica and chalcogenide glasses, sparingly soluble salts, and single crystal materials. Today, however, most research focuses on polymeric membrane materials because it allows one to tune the selectivity of the sensor on the basis of host-guest chemistry principles. ${ }^{3-5}$ Many hundred different such receptors have been designed, and some of the most successful ones are commercially available. Normally, the receptor is doped, at a molar excess relative to a lipophilic ion-exchanger, into a hydrophobic membrane, which for simplicity can be regarded as a hydrophobic solvent of high viscosity. ${ }^{3}$

Today, the emf response of such membranes is primarily described in simple terms according to the so-called phase boundary or galvanic potential model, ${ }^{6,7}$ which assumes localized equilibrium across the interfaces and disregards potential changes in the interior of the membrane or sample solution. ${ }^{8,9}$ The potential at the sample-membrane phase boundary, for instance, is formulated as:
$E_{P B}=E_{I}^{0}+\frac{R T}{z_{I} F} \ln \frac{a_{I}(a q)}{a_{I}(\text { org })}$

where $\mathrm{R}, \mathrm{T}$ and $\mathrm{F}$ are the universal gas constant, the absolute temperature and the Faraday constant, respectively, and $a_{I}(a q)$ and $a_{I}($ org $)$ are the activity of the ion $I$ (with charge $\left.z_{I}\right)$ in the aqueous and organic phase boundaries. The standard potential, $E_{I}^{0}$, is a direct function of the free energy of transfer for the ion $I$, which can be written as a function of the chemical standard potentials in either phase:

$E_{I}^{0}=\frac{\mu_{I}^{0}(a q)-\mu_{I}^{0}(\text { org })}{z_{I} F}$

Several characteristics can be noted from equation 1. First, it is apparent that equation 1 reduces only to the well known Nernst equation for ion-selective electrodes, written as

$$
e m f=K+\frac{R T}{z_{I} F} \ln a_{I}(a q)
$$

if the ion activity in the organic phase boundary, $a_{I}($ org $)$, is relatively constant. This is primarily accomplished by the presence of a lipophilic ion-exchanger in the membrane. ${ }^{10}$ If this ion-exchanger is missing, the membrane loses its so-called permselectivity and a Nernstian response slope cannot be observed. ${ }^{11}$ Early polymeric membrane electrodes did not contain added ion-exchangers ${ }^{12}$ and functioned only satisfactorily because the membrane materials were sufficiently impure to contain ion-exchanger functionalities. ${ }^{13}$ Indeed, later experiments with purified membranes containing the well established receptor Valinomycin confirmed the expected breakdown of the desired sensing characteristics. ${ }^{14}$

\section{Selectivity}

While the ion-exchanger is added to aid in the desired Donnan exclusion (leading to large imbalance of extracted cations and anions in the membrane), the role of the receptor (or ionophore) is that of enhancing the selectivity over ions of the same charge sign. Simple membranes containing only ion-exchanger always favor more lipophilic ions over less lipophilic ones. ${ }^{15}$ This is known as the Hofmeister selectivity series. Ionophores selectively bind to one ion over others and can reverse this sequence, making polymeric membrane electrodes much more versatile than what their underlying materials suggest. In mathematical terms, the presence of an ionophore should decrease $a_{t}(\mathrm{org})$ in equation 1 and result in larger phase boundary potentials at the outer interface. ${ }^{3}$

One may argue that this would be a perfect way to assess binding constants in ion-selective membranes. Indeed, this can be accomplished if the outer phase 
boundary potential can be uncoupled from the one at the inner side of the membrane. A number of experimental techniques have been reported to accomplish this. ${ }^{16-19}$ In one versatile protocol, one fabricates two membranes of different composition, typically one with and one without the ionophore of interest. ${ }^{18,20}$ The membrane potential of the fused membrane segment is then compared to that of the individual segments and related to the complex formation constant of the ionophore. Complex formation constants $(\beta)$ calculated from such techniques can be very large, often with $c a \cdot \log \beta=10$, depending on the ionophore and ion under study. Such methods are useful in assisting rational receptor design because the resulting data give direct feedback on the strength of the ion-receptor interaction in the final system of interest. ${ }^{21}$

Of course, binding constants will translate into sensor selectivity. The selectivity is traditionally described by the so-called selectivity coefficient, which has its roots in the Nikolskii equation. ${ }^{5}$ This selectivity coefficient is, if properly measured, a direct function of the standard potential differences and ratios of ion activities in the organic phase boundaries as defined in equation $1:^{22}$

$K_{I J}^{p o t}=\frac{a_{I}(\operatorname{org})}{a_{J}(\operatorname{org})}\left\{\frac{z_{I} F}{R T} \exp \left(E_{J}^{0}-E_{I}^{0}\right)\right\}$

where $I$ and $J$ in $K_{I J}^{\text {pot }}$ are the primary and interfering ion, respectively. Better selectivity for $I$ over $J$ will give smaller
$K_{I J}^{p o t}$ values. Note that the characteristics of the ionophore have primarily a bearing on the activity ratio shown in equation 4 . The rest of the equation is a function of ion solvation characteristics.

\section{Measuring Ionophore Binding Constants}

Careful selectivity measurements on unmodified polymeric membranes can also be used to extract binding constant data. ${ }^{19}$ If one ion can be identified to exhibit negligible binding characteristics with the ionophore, this ion may be used as a reference ion. Measurements on membranes with and without the ionophore will give the same phase boundary potential for the reference ion and can be used to calculate binding constants. Note that the assumption required here may be tested with the segmented sandwich method mentioned earlier.

This so-called reference ion method has recently been illustrated to screen a number of silver-selective ionophores for use in polymer membrane ISEs, see Figure $1 .{ }^{21}$ In this example, the tetraethylammonium ion was chosen as the reference ion, separate calibration curves to a variety of different ions including $\mathrm{Ag}^{+}$were recorded. As shown in Figure 1, the response to the reference ion is suppressed relative to silver in a number of cases, suggesting a very high binding selectivity for that ionophore. Adequately high binding constants are a key requirement for the successful development of truly useful ISE membranes, and can be
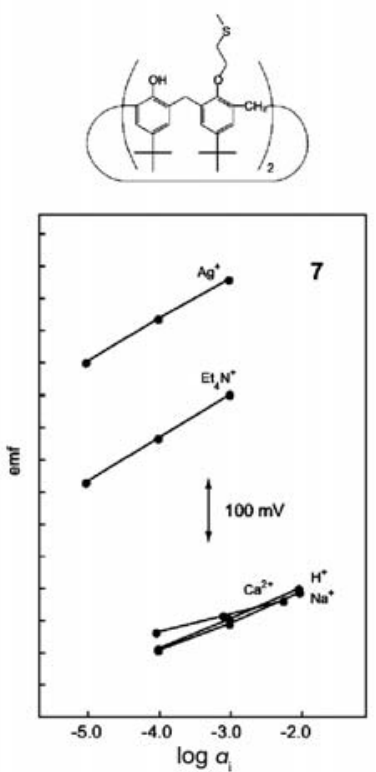
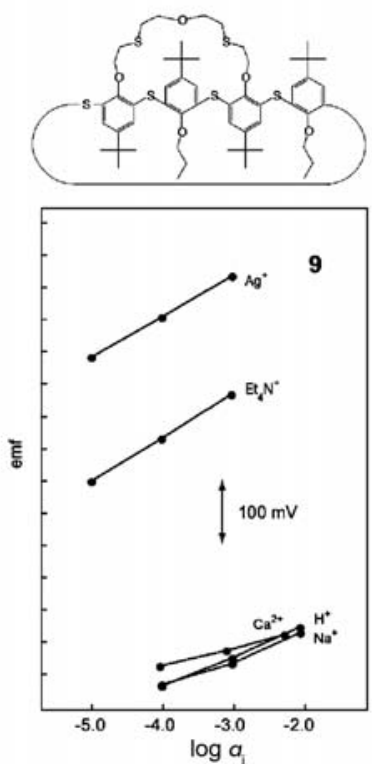
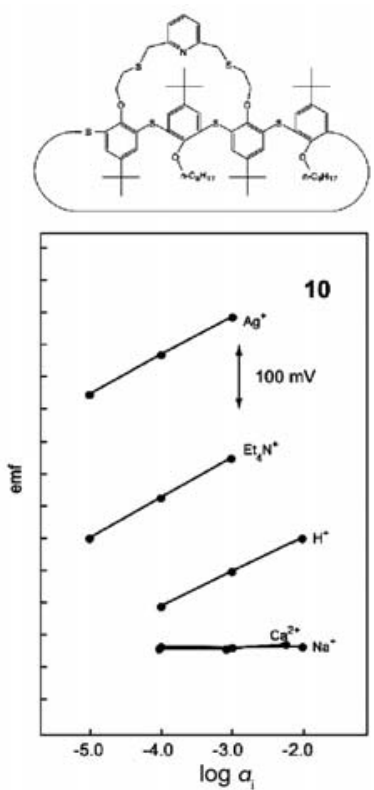

Figure 1. Potentiometric response behavior of membranes containing a range of potential silver ion-selective ionophores. Note that the separate calibration curves can be used to determine the membrane selectivity if Nernstian response slopes are observed for each ion. The inclusion of the lipophilic ion tetraethylammonium is used to estimate the binding constant of the ionophore (figure adapted from the reference 21). Structures: 7, 5,11,17,23-tetra-tertbutyl-25,27-di(2-methylthio)ethoxycalix[4]arene); 9, 1,3-alt-5,11,17,23-tetra-tert-butyl-25,27-dipropoxy-26,28-(3,9-dithia-6-oxaundec-1,11-diyloxy) thiacalix[4] arene; 10, 1,3-alt-5,11,17,23-tetra-tert-butyl-25,27-di-n-octyloxy-26,28-[pyridine-2,6-bis(methylthioethoxy)] thiacalix[4] arene. 
estimated with relative ease using some of the techniques mentioned here.

\section{Detection Limit}

In ideal cases (high sample concentrations) where concentration polarizations in the aqueous phase boundary can be neglected, the membrane selectivity directly dictates the detection limit of the ISE. ${ }^{23,24}$ The emf in the absence of primary ions in the sample is fully dictated by the response of the ISE to any other ions that are present. The detection limit of ISEs is historically defined in a very different way from other analytical techniques. ${ }^{23}$ Instead of using some multiple of the standard deviation of the noise, the detection limit is defined as the cross-section of the extrapolated linear segments of the calibration curve. In well behaved cases, this means that the detection limit is found where the extrapolated Nernstian response of the electrode meets the background potential in the absence of primary ions. One may use ion-exchange theory to analyze this region and realize that the deviation of the emf from Nernstian behavior is caused by a displacement of primary ions by interfering ones in the organic phase boundary, $a_{I}(\mathrm{org})$ diminishes in equation 1 . At the detection limit, exactly half of the primary ions in the phase boundary have been exchanged for interfering ions (for ions of the same charge). ${ }^{25}$

In cases of high selectivity, the calculated detection limit on the basis of equilibrium ion-exchange should be extremely low. For a selectivity coefficients of $\log K_{I, H}^{p o t}=-10$, for instance, an ISE should give a $10^{-17} \mathrm{~mol} \mathrm{~L}^{-1}$ detection limit in a background of pure water with a concentration of $\mathrm{H}^{+}$ of $10^{-7}$ mol L-1.25 Such low detection limits have never been observed in samples containing no ion buffer. The reason for this discrepancy originates in the fact that ionexchange reactions generate counterdiffusion fluxes at zero current. Primary ions are exchanged from the membrane and diffuse away from the membrane surface into the sample bulk, while exchanging interfering ions diffuse in the opposite direction. This process leads to concentration polarizations at the membrane surface, and to an effective accumulation of primary ions relative to the bulk sample composition. ${ }^{25,26}$ Since ISEs are calibrated relative to the bulk sample composition, this leads to a deviation from an apparent Nernstian slope as well: $a_{I}(a q)$ in equation 1 becomes independent of its value in the sample bulk. This process leads to a bias in the detection limit and in the calculated selectivity coefficients that can amount to many orders of magnitude. . $5,27,28^{2}$

The selectivity bias can be quite easily eliminated by various means, including the use of ion buffers in the sample, ${ }^{29}$ membranes that have not been exposed to the most preferred ions before characterization, ${ }^{30}$ and membranes that exhibit a siphoning effect in direction of the inner solution. ${ }^{31}$ Selectivity coefficients obtained with any of these methodologies often reflect a much better selectivity than with traditional, biased protocols. ${ }^{32}$ For comparative data, see the reference. ${ }^{33}$

The detection limit bias is much more difficult to eliminate because an ion flux in any direction will invariably deteriorate the Nernstian emf response. Ion-selective membranes placed between two aqueous electrolytes will always exhibit some bias if there is a driving force for transport across the membrane. This has been extensively modeled in recent years, and the detection limit can be predicted according to explicit equations if the system is at steady-state. ${ }^{25}$ For ions of the same charge, for instance, the following equation describes a simple optimum case where no ion-exchange or coextraction takes place at the inner membrane side: ${ }^{25}$

$\log c_{I}(D L)=\frac{1}{2} \log \left\{\frac{D_{\text {org }} \delta_{a q} R_{T}}{D_{a q} \delta_{\text {org }} z_{I}} K_{I J}^{\text {pot }} c_{J}\right\}$

where $D$ and $\delta$ are the diffusion coefficients and diffusion layer thicknesses in the indicated phases and $R_{\mathrm{T}}$ is the concentration of the ion-exchanger. A careful optimization of numerous ISE membranes have given rise to detection limits that now routinely reach the nanomolar concentration range or lower. ${ }^{33}$ To illustrate this, the ionophore 9 characterized in Figure 1 in terms of its selectivity and binding constant was used to achieve ISE membranes with unsurpassed detection limits for silver ions. As shown in Figure 2, detection limits approach $10^{-11} \mathrm{~mol} \mathrm{~L}^{-1}$ for membranes containing this ionophore. ${ }^{21}$

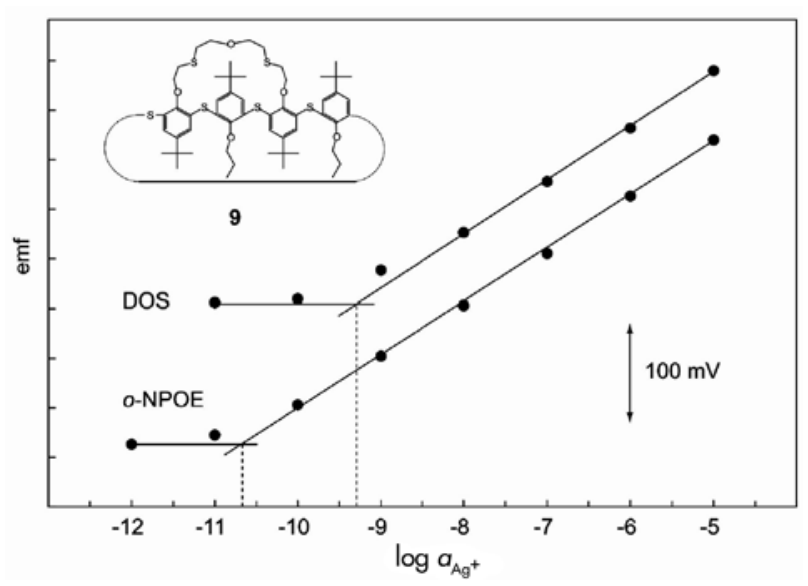

Figure 2. Optimized polymeric membrane for the detection of silver at trace levels (see also Figure 1), achieving a detection limit of $3 \times 10^{-11} \mathrm{~mol} \mathrm{~L}^{-1} \mathrm{Ag}^{+}$in unbuffered samples (figure adapted from the reference 21). The plasticizers DOS (bis(2-ethylhexyl)sebacate) and $o$-NPOE (ortho-nitrophenyloctylether) were used in this work. 


\section{Solid Contact ISEs}

Further improvements in the detection limit are likely possible by replacing the traditional internal filling solution of the membrane by a solid inner contact. This would ideally give rise to a two phase extraction system and yield detection limits that are also more robust because no internal solution composition needs to be optimized. Early solid contact or coated wire electrodes did not exhibit attractive detection limits ${ }^{34}$ and it was recently suggested that a poor adhesion between membrane and underlying electron conductor can lead to the formation of a water layer, ${ }^{35}$ effectively acting as an electrolyte reservoir that changes as a function of the sample composition. This leads to potential drifts and unattractive detection limits. Recent work by De Marco confirmed the presence of such a water layer by neutron scattering. ${ }^{36}$ Successful work has therefore aimed at applying conducting polymers as adequate ion to electron transducers. ${ }^{37}$ In a recent attractive example, hydrophobic poly(3-octylthiophene) was shown to be attractive for the fabrication of solid contact ISEs for a number of different ions with subnanomolar detection limits. ${ }^{38}$ While it is still important to follow strict conditioning protocols, such systems alleviate the need for the optimization of an internal filling solution and are likely the most attractive systems for end users. ${ }^{39}$ Figure 3 demonstrates that solid contact ISEs exhibit reproducible behavior at the nanomolar concentration range, shown here for the detection of silver ions. ${ }^{40}$

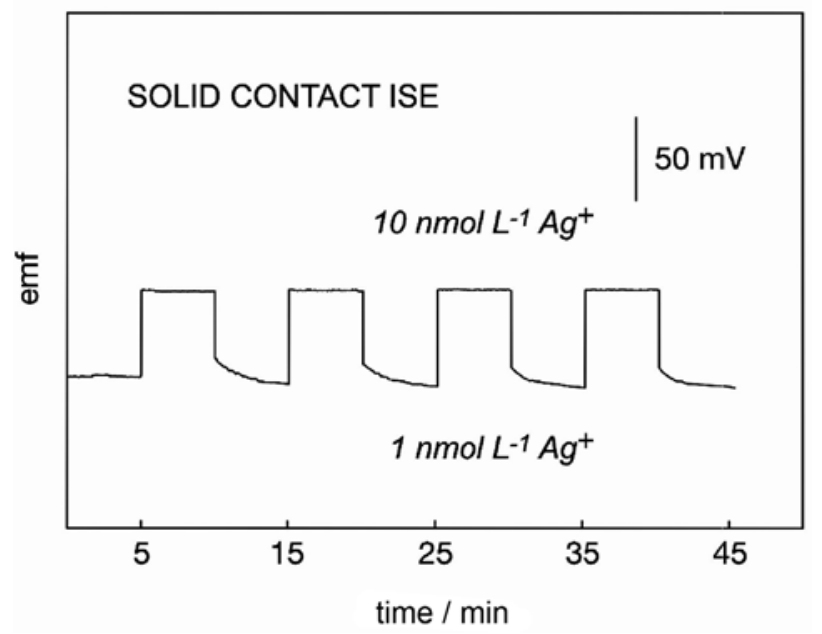

Figure 3. Potential reproducibility of solid contact silver ion-selective microelectrode in contact with $1 \mathrm{nmol} \mathrm{L}^{-1}$ to $10 \mathrm{nmol} \mathrm{L}^{-1}$ sample solutions (figure adapted from the reference 40).

\section{ISEs for Small Sample Volumes}

Potentiometry is uniquely suited for detection in samples of small volumes. ${ }^{41}$ This is illustrated in equation
1 , where the emf is a direct function of the ion activity. If the biases described above can be effectively eliminated, potentiometry may be suited to detect ultra-small quantities of material in confined samples. In fact, potentiometric microelectrodes have already been routinely used for the detection of electrolytes in single cells, ${ }^{42}$ which already exhibit sample diameters on the order of tens of micrometers. A new application made possible by the recent developments stated above is the detection of low concentrations in small samples. One example recently demonstrated the detectability of 300 attomol of ions in a $3 \mu \mathrm{L}$ sample volume, in a design similar to segmented flow analysis where a sample droplet was confined by two air bubbles and moved to the detection spot. ${ }^{43}$ More recent work aimed at bioanalysis performed calibration curves in $200 \mu \mathrm{L}$ microtiter plates with solid contact potentiometric microelectrodes and demonstrated 200 femtomol detection limits, this time for cadmium ions. ${ }^{44}$ In these applications, a high surface to volume ratio and possible sample contamination requires very careful approaches and selection of materials, analogous to other ultra-trace level techniques.

\section{ISEs for Ultrasensitive Bioanalysis}

The progress in low detection limit ISEs described above makes them potentially attractive detectors for bioanalysis. For this to work, the biorecognition event needs to be amplified to yield a multitude of ions that can be detected potentiometrically. Recent work in this direction aimed at exploring whether potentiometry can compete with more established ultrasensitive electrochemical techniques such as adsorptive stripping voltammetry. ${ }^{45}$ An initial example demonstrated the utility of potentiometry in a heterogeneous sandwich immunoassay for the detection of IgG. ${ }^{46}$ The secondary antibody was labeled with gold nanoparticles, which were chemically plated with silver after the assay. The oxidative release of silver ions was then measured with solid contact potentiometric microelectrodes. A similar scheme was later reported with cadmium-selective electrodes, using cadmium selenide nanoparticles that were oxidatively released into the solution without a chemical enhancement step. ${ }^{47}$ The resulting detection limits for IgG (less than $10 \mathrm{fmol}$ in $150 \mu \mathrm{L}$ samples) were more attractive than in the earlier approach, most likely because of less nonspecific signal (see Figure 4). This general approach is currently being extended to the detection of DNA hybridization and the use of aptamers to detect thrombin. In these cases, cadmium solid contact ISEs are used, and the resulting detection limits are far superior compared to stripping voltammetric 
detection using the same nanoparticle labels. ${ }^{48}$ This should pave the way for a more general acceptance of ultrasensitive potentiometric affinity bioassays that are based on surprisingly simple instrumentation.

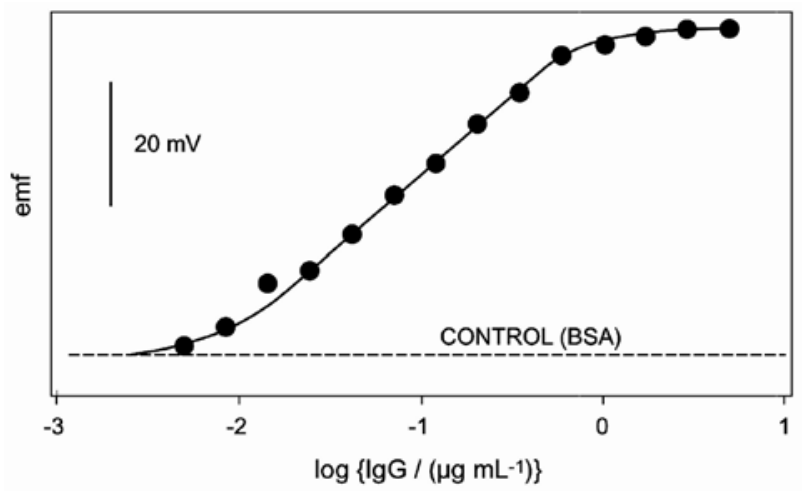

Figure 4. Calibration curve for the determination of $\mathrm{IgG}$ using potentiometric microsensors via CdSe quantum dot labels in $150 \mu \mathrm{L}$ sample volumes in a sandwich immunoassay format (figure adapted from the reference 47). The signal for the control (BSA, Bovin Serum Albumin) is shown as a dotted line.

\section{Beyond Direct Potentiometry}

Unfortunately, there are numerous situations in which direct potentiometry is undesired for practical measurements. The direct relationship between sample activity and signal can be of great advantage, but the technique does not intrinsically compensate for potential drifts. These may originate from temperature fluctuations, changes in the membrane chemistry because of fouling processes, clogging of the liquid junction at the reference electrode, and other issues. In routine clinical analysis, frequent single point recalibrations are performed to correct for potential drifts. However, numerous applications exist where altering the sample composition for calibration purposes is not possible or desired.

Recently, a new measurement principle for ion-selective membranes has been introduced where the magnitude of the observed potential is unimportant and changes in the sample composition for calibration or standard addition purposes can be avoided as well. This principle is termed backside calibration potentiometry. ${ }^{49}$

In this technique the sample side of the sensor is not altered for calibration purposes. The concept uses thin supported ion-selective membranes across which steadystate concentration gradients are established in a matter of seconds, ${ }^{50}$ see Figure 5. In this experiment, the inner solution composition is altered until the concentration gradient across the membrane reduces to zero, which is similar in concept to the zeroing of a Wheatstone bridge. This is here accomplished by changing the stirring rate of the two aqueous solutions and monitoring the potential: no influence of stirring on the emf is expected once the ion concentration gradients disappear. What makes this technique unique is that the magnitude of the potential is not important in the measurement. Still, the approach does not allow one to determine single ion activities, which would be thermodynamically impossible. Instead, it has been shown that one determines the activity ratio of analyte ion to its dominant interfering ion because the concentration gradients are dictated by ion-exchange equilibrium processes. ${ }^{49}$ If the activity of the interferent is known, the analyte ion activity may be calculated. The technique has been shown to determine lead ions in samples buffered at $\mathrm{pH} 4$, with hydrogen ions the dominant interferent. ${ }^{49}$ The lead concentrations found by this technique in environmental water samples corresponded quantitatively to independently measured values.

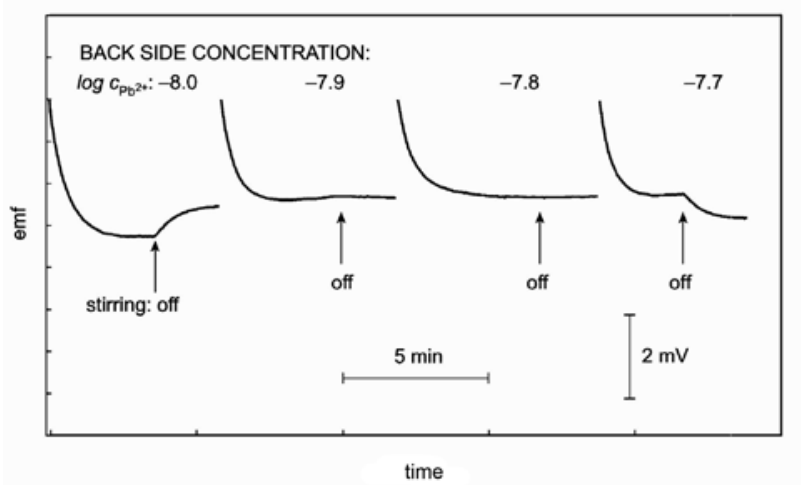

Figure 5. Backside calibration potentiometry: Evaluation of transport symmetry across ion-selective electrode membranes via stirring experiments. No stirring is observed if the composition of the solutions at the front and back of the membrane is equal (figure adapted from the reference 49). In this example, the dominant exchanging ion is $\mathrm{H}^{+}$at $\mathrm{pH} 4.0$.

\section{Beyond Potentiometry: Pulstrodes}

Polymeric ion-selective membranes can also be manipulated electrochemically to yield improved operational characteristics or to give information about the sample that cannot easily be obtained by means of zero current potentiometry. For example, a current passed across the membrane results in a defined flux of ions that can have a multitude of applications. It has been used to electrochemically compensate for spontaneous ion fluxes across the membrane (see above), thereby lowering the detection limit of the electrode to ultra-trace levels without chemical optimization. ${ }^{51}$ However, this approach has not yet been demonstrated on samples of unknown composition. A defined ion flux can also be used to apply such membranes as coulometric actuators for sample delivery purposes. 
This was recently demonstrated with calcium, barium and silver selective membranes. ${ }^{52}$ This work included the complexometric back titration of nickel with calcium with a coulometric calcium-selective electrode in conjunction with a potentiometric calcium membrane as detector. Such approaches do not require complicated fluidics or standardization procedures and are potentially very attractive.

Current control can also be used to improve the sensing characteristics of polymer membrane ion-selective electrodes. ${ }^{53}$ Essentially, the extraction of analyte ions from the sample is not controlled chemically by an ion-exchanger, but imposed electrochemically. For this reason, such membranes are ideally void of ion-exchanger properties. The measurement may occur in three stages. ${ }^{54} \mathrm{In}$ step 1, a short current pulse drives ions from the sample into the membrane. In step 2, the potential is measured under zero current conditions in complete analogy to traditional potentiometry. This may avoid problems associated with resistance changes in the cell, which may bias the observed potential if measured during the first pulse. In step 3, a potential is applied that drives all previously extracted ions back into the aqueous solution, regenerating the membrane.

There are two key features that set pulstrodes apart from zero current potentiometry. One is that ion extraction is no longer spontaneous but controlled and triggered by the instrument, which means that irreversible extraction phenomena can be more easily kept under control. Prime examples are the development of reversible polyion sensors ${ }^{55}$ and membranes in contact with dilute, but highly preferred interfering ions that would normally mask the response of the ISE to the ion of interest. ${ }^{56}$ The second feature is that concentration polarizations in the aqueous phase boundary may be performed in controlled fashion. This allows one to drastically increase the sensitivity of the measurement, sometimes by more than an order of magnitude relative to that dictated by the Nernst equation. This was for example realized with a calciumselective membrane, which was tuned to give a nearly $200 \mathrm{mV}$ potential change for a just 2.4 fold concentration increase. ${ }^{57}$ The Nernst equation predicts just $11.3 \mathrm{mV}$ for the same concentration change. This is possible because of localized analyte depletion processes at the membrane surface.

It is now also possible to learn more about the sample because of the perturbation in the aqueous phase boundary. Very recently, a direct sensing scheme was proposed for total acidity, using $\mathrm{H}^{+}$-selective polymeric membranes that are galvanostatically controlled. ${ }^{58}$ The sensor is here interrogated in a localized flash titration mode. The potential is monitored until an endpoint is observed, and this time (on the order of $1 \mathrm{~s}$ ) is used to quantify the acid concentration in the sample (see Figure 6). This is possible because the hydronium ion flux imposed in direction of the membrane is carried by the diffusion of the weak acid. The diffusion layer thickness expands continuously in the first few seconds of the perturbation experiment and results in a critical time at which the acid can no longer sustain the imposed flux. Note that the subsequent baseline potential expels nearly all previously extracted hydronium ions into sample, making this technique nearly perturbation free. This principle can be easily expanded to other ions if selective chemistries can be identified to detect them with polymer membrane ion-selective electrodes.

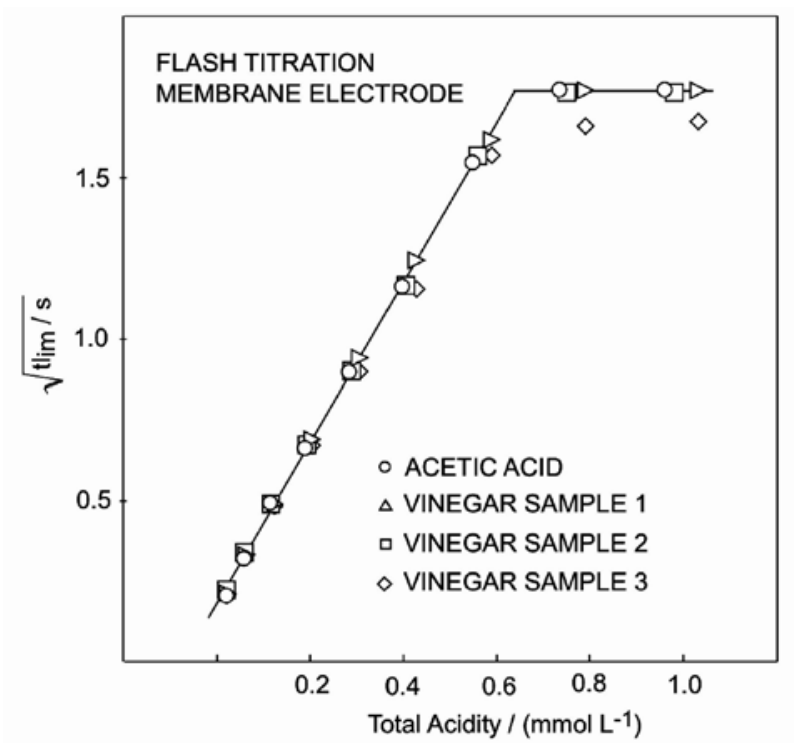

Figure 6. Direct chronopotentiometric flash titration of weak acids at polymer membrane $\mathrm{pH}$ electrodes gives direct information on the total acidity of the sample without the need for traditional sampling (figure adapted from the reference 58).

\section{Conclusions}

Polymeric membrane ion-selective electrodes belong to the better understood class of chemical sensors today, and have had a profound impact in the world we live in. Despite the common misconception that ISEs are a mature, even outdated technology, tremendous advances have been made in the last few years that have transformed the field and made it again fashionable. ISEs are one of the very few tools available that can be used for ion activity measurements. It is now possible to use these at ultra-trace levels, in confined volumes. While the list of ions that can be detected at trace levels is growing continuously, the bottleneck is clearly in the availability for excellent receptors with high binding strength and selectivity. However, ISEs can be used to 
detect a wide variety of biomolecules via affinity assays labeled with nanoparticles that yield detectable ions after dissolution. Even though this research is very young, ISE detection can already compete with stripping voltammetry. Other, rather playful and useful directions for ion-selective electrodes have been noted, including the potentially powerful concept of backside calibration potentiometry, controlled current coulometry and controlled current chronopotentiometry (pulstrodes). These approaches open new attractive horizons for these selective materials and further expand the field.

\section{Acknowledgments}

This research has been supported by the National Institutes of Health through grants EB002189 and GM07178.

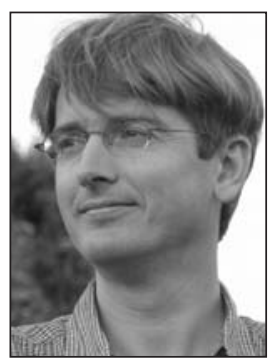

Eric Bakker is a Professor of Nanochemistry and Director of the Nanochemistry Research Institute at Curtin University in Perth, Western Australia. He earned his doctoral degree with Wilhelm Simon at the Swiss Federal Institute of Technology (ETH) in Zurich, Switzerland, and spent two years at the University of Michigan as a postdoctoral fellow before serving on the faculty of Auburn University and later Purdue University in the United States. His research interests are in the development of chemical sensing concepts, particularly electrochemical sensors based on polymeric sensing phases and fluorescent bead based sensors. He has published more than 160 papers on the subject.

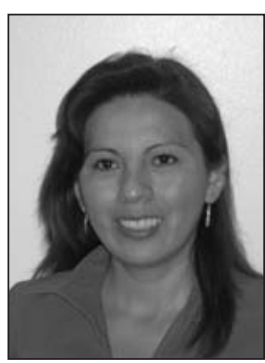

Karin Y. Chumbimuni-Torres is a postdoctoral researcher at Purdue University. A native of Peru, she earned her PhD with prof. Lauro Kubota at UNICAMP, São Paulo, Brazil, before joining the group of Dr. Eric Bakker at Purdue University. Her current research focus is on the development of ultrasensitive potentiometric detection techniques for bioanalysis via nanoparticles labels in confined sample volumes and the application of this technology to environmental analysis. During her postdoctoral stay she also worked at Arizona State University in the group of Dr. Joseph Wang.

\section{References}

1. Covington, A. K.; Kataky, R.; J. Chem. Soc. Faraday Trans. 1993, 89, 369.

2. Ross, J. W.; Science 1967, 156, 1378.

3. Bakker, E.; Bühlmann, P.; Pretsch, E.; Chem. Rev. 1997, 97, 3083.

4. Bühlmann, P.; Pretsch, E.; Bakker, E.; Chem. Rev. 1998, 98, 1593.

5. Umezawa, Y.; Handbook of Ion-Selective Electrodes: Selectivity Coefficients, CRC Press: Boca Raton, Ann Arbor, Boston, 1990.

6. Guggenheim, E. A.; J. Phys. Chem. 1929, 33, 842.

7. Guggenheim, E. A.; J. Phys. Chem. 1930, 34, 1540.

8. Theorell, T.; Proc. Soc. Exp. Biol. Med. 1935, 33, 282.

9. Meyer, K. H.; Sievers, J. -F.; Helv. Chim. Acta 1936, 19, 649.

10. Bakker, E.; Nägele, M.; Schaller, U.; Pretsch, E.; Electroanalysis $1995,7,817$.

11. Karpfen, F. M.; Randles, J. E. B.; Trans. Faraday Soc. 1953, $49,823$.

12. Morf, W. E.; Ammann, D.; Pretsch, E.; Simon, W.; Pure Appl. Chem. 1973, 36, 421.

13. van den Berg, A.; Reinhoudt, D. N.; Skowronska-Ptasinska, M.; Sudholter, E.; Van der Wal, P. D.; Anal. Chem. 1987, 59, 2826.

14. Bühlmann, P.; Yajima, S.; Tohda, K.; Umezawa, K.; Nishizawa, S.; Umezawa, Y.; Electroanalysis 1995, 7, 811.

15. Morf, W. E.; The Principles of Ion-Selective Electrodes and of Membrane Transport, Elsevier: New York, 1981.

16. Bakker, E.; Willer, M.; Lerchi, M.; Seiler, K.; Pretsch, E.; Anal. Chem. 1994, 66, 516.

17. Bakker, E.; Pretsch, E.; J. Electrochem. Soc. 1997, 144, L125.

18. Mi, Y.; Bakker, E.; Anal. Chem. 1999, 71, 5279.

19. Ceresa, A.; Pretsch, E.; Anal. Chim. Acta 1999, 395, 41.

20. Shultz, M. M.; Stefanova, O. K.; Mokrov, S. B.; Mikhelson, K. N.; Anal. Chem. 2002, 74, 510.

21. Szigeti, Z.; Malon, A.; Vigassy, T.; Csokai, V.; Grun, A.; Wygladacz, K.; Ye, N.; Xu, C.; Chebny, V.; Bitter, I.; Rathore, R.; Bakker, E.; Pretsch, E.; Anal. Chim. Acta 2006, 572, 1.

22. Bakker, E.; Pretsch, E.; Bühlmann, P.; Anal. Chem. 2000, 72, 1127.

23. Buck, R. P.; Lindner, E.; Pure Appl. Chem. 1995, 66, 2527.

24. Bakker, E.; Willer, M.; Pretsch, E.; Anal. Chim. Acta 1993, 282, 265.

25. Ceresa, A.; Radu, A.; Peper, S.; Bakker, E.; Pretsch, E.; Anal. Chem. 2002, 74, 4027.

26. Mathison, S.; Bakker, E.; Anal. Chem. 1998, 70, 303.

27. Sokalski, T.; Zwickl, T.; Bakker, E.; Pretsch, E.; Anal. Chem. 1999, 71, 1204. 
28. Morf, W. E.; Badertscher, M.; Zwickl, T.; de Rooij, N. F.; Pretsch, E.; J. Phys. Chem. 1999, 103, 11346.

29. Hulanicki, A.; Sokalski, T.; Lewenstam, A.; Mikrochim. Acta 1988, 111, 119.

30. Bakker, E.; Anal. Chem. 1997, 69, 1061.

31. Sokalski, T.; Ceresa, A.; Zwickl, T.; Pretsch, E.; J. Am. Chem. Soc. 1997, 119, 11347.

32. Guilbault, G. G.; Durst, R. A.; Frant, M. S.; Freiser, H.; Hansen, E. H.; Light, T. S.; Pungor, E.; Rechnitz, G.; Rice, N. M.; Rohm, T. J.; Simon, W.; Thomas, J. D. R.; Pure Appl. Chem. 1976, 48, 127.

33. Bakker, E.; Pretsch, E.; Trends Anal. Chem. 2005, 24, 199.

34. Cattrall, R. W.; Hamilon, I. C.; Ion-Sel. Electr. Rev. 1984, 6, 125.

35. Fibbioli, M.; Morf, W. E.; Badertscher, M.; de Rooij, N. F.; Pretsch, E.; Electroanalysis 2000, 12, 1286.

36. Marco, R. D.; Veder, J. -P.; Clarke, G.; Nelson, A.; Prince, K.; Pretsch, E.; Bakker, E.; Phys. Chem. Chem. Phys. 2008, 10, 73.

37. Michalska, A.; Konopka, A.; Maj-Zurawska, M.; Anal. Chem. 2003, 75, 141.

38. Sutter, J.; Radu, A.; Peper, S.; Bakker, E.; Pretsch, E.; Anal. Chim. Acta 2004, 523, 53.

39. Chumbimuni-Torres, K.; Rubinova, N.; Radu, A.; Kubota, L. T.; Bakker, E.; Anal. Chem. 2006, 78, 1318.

40. Rubinova, N.; Chumbimuni-Torres, K.; Bakker, E.; Sens. Actuators, B 2007, 121, 135.

41. Manz, A.; Graber, N.; Widmer, H. M.; Sens. Actuators, B 1990, $1,244$.

42. Ammann, D.; Ion-Selective Microelectrodes, Springer: Berlin, 1986.

43. Malon, A.; Vigassy, T.; Bakker, E.; Pretsch, E.; J. Am. Chem. Soc. 2006, 128, 8154.
44. Numnuam, A.; Chumbimuni-Torres, K. Y.; Xiang, Y.; Bash, R.; Thavarungkul, P.; Kanatharana, P.; Pretsch, E.; Wang, J.; Bakker, E.; Anal. Chem. 2008, 80, 707.

45. Wang, J.; Liu, G.; Polsky, R.; Merkoçi, A.; Electrochem. Commun. 2002, 4, 722.

46. Chumbimuni-Torres, K. Y.; Rubinova, N.; Pretsch, E.; Wang, J.; Bakker, E.; J. Am. Chem. Soc. 2006, 128, 13676.

47. Thürer, R.; Vigassy, T.; Hirayama, M.; Wang, J.; Bakker, E.; Pretsch, E.; Anal. Chem. 2007, 79, 5107.

48. Numnuam, A.; Chumbimuni-Torres, K. Y.; Xiang, Y.; Bash, R.; Thavarungkul, P.; Kanatharana, P.; Pretsch, E.; Wang, J.; Bakker, E.; J. Am. Chem. Soc. 2008, 130, 410.

49. Malon, A.; Bakker, E.; Pretsch, E.; Anal. Chem. 2007, 79, 632.

50. Tompa, K.; Birbaum, K.; Malon, A.; Vigassy, T.; Bakker, E.; Pretsch, E.; Anal. Chem. 2005, 77, 7801.

51. Pergel, E.; Gyurcsanyi, R. E.; Toth, K.; Lindner, E.; Anal. Chem. 2001, 73, 4249.

52. Bhakthavatsalam, V.; Shvarev, A.; Bakker, E.; Analyst 2006, $131,895$.

53. Shvarev, A.; Bakker, E.; Anal. Chem. 2003, 75, 4541.

54. Makarychev-Mikhailov, S.; Shvarev, A.; Bakker, E.; J. Am. Chem. Soc. 2004, 126, 10548.

55. Shvarev, A.; Bakker, E.; Anal. Chem. 2005, 77, 5221.

56. Gemene, K. L.; Shvarev, A.; Bakker, E.; Anal. Chim. Acta 2007, $583,190$.

57. Makarychev-Mikhailov, S.; Shvarev, A.; Bakker, E.; Anal. Chem. 2006, 78, 2744.

58. Gemene, K. L.; Bakker, E.; Anal. Chem., in press.

Received: October 11, 2007 Web Release Date: March 28, 2008 